\title{
Thinking on Improving Teaching Quality and Promoting the Connotation Development of Universities
}

\author{
Xiaowei Feng \\ Ideological and Political Department, Xi'an Peihua University, Xi'an, 710125, China \\ 465499468@qq.163.com
}

Keywords: Teaching quality; University; Connotation development

\begin{abstract}
Teaching quality is the core element and fundamental sign of the connotation development of universities. Only by improving teaching quality can we truly promote the connotation development of education in universities. Therefore, we should deepen our understanding and take teaching quality as the sign of measuring the construction of universities. Following the rule, let the university construction revolve the teaching quality scientific operation; Find the right grip and strive to improve the teaching quality in the development of university connotation.

Accelerating the construction of first-class universities and first-class disciplines and realizing the connotation development of education is the goal of education of higher institutions in the new era. To achieve the above goals, we must grasp the teaching quality, which is the core element and the fundamental sign of the connotation development of universities, and urge them to develop in a self-reliant and sustainable way.
\end{abstract}

\section{Deepen the Understanding, Indeed Take the Teaching Quality as the Sign of Measuring the University Construction}

Teaching quality is the life of universities, and is the fundamental sign to measure the construction level of universities. Therefore, it is necessary to take improving teaching quality as the eternal theme of university construction, so as to provide strong guarantee for the survival, competition and development of universities.

\section{A. University Survival Depends on Teaching Quality}

University are bases of talent cultivation. Teaching is the main practice of cultivating talents. Improving teaching quality is the foundation of university construction. Teaching quality is the result of the comprehensive function of each element in the personnel training of universities. Teaching quality includes teachers' teaching ability, students' learning ability, as well as the coordination ability of leaders and the organizing and disciplining ability of authorities. To improve the quality of teaching, we should not only improve the quality of teachers, but also enhance the level of running schools. The mission of universities is to train socialist builders and successors. If the teaching quality is low and the trained talents are unqualified, the university will lose its value. Therefore, the quality of teaching is related to the quality of talent cultivation and determines the survival of colleges and universities.

\section{B. Competition in Universities Depends on the Quality of Teaching.}

Competition among universities is the competition of teaching quality. From the perspective of the development of higher education, the competition among colleges and universities, especially those of the same type, is the general trend. After the Ministry of Education put forward the goal of "double-first-class" construction, some colleges and universities have invested a lot, the starting point of infrastructure construction is very high, and the confidence of running a good school is very high. The competition among colleges and universities is very fierce, and all strive to achieve outstanding results in the construction and development. In this case, colleges and universities must establish the concept that teaching quality is the core competitiveness, and do everything possible to improve the quality of teaching. In the personnel training, professional construction and other work 
to ensure that their respective advantages remain unchanged, and strive to make a difference in the competition.

\section{The Development of Universities Benefits from the Quality of Teaching}

Teaching quality is the decisive factor in the development of colleges and universities, and is the eternal vitality of university construction. For a long time, colleges and universities in China have taken a series of effective measures in the construction of disciplines and specialties, the staffing of teachers, the guarantee of teaching management, and the construction of infrastructure, so as to improve the quality of teaching. It is precisely because of this that famous universities, such as Peking University and Tsinghua University, have emerged in China. At present, socialism with Chinese characteristics has entered a new era, and the development of higher education in China has entered a new starting point. It is a new task for us to speed up the construction of first-class universities and disciplines and train socialist builders and successors with all-round development of morality, intelligence, physique and beauty. To meet the new requirements of the times and promote the sustainable development of colleges and universities, it is still necessary to improve the quality of teaching as a support.

\section{Follow the Rules and Really Let the Construction Universities Run Around the Teaching Quality Scientifically.}

Teaching in Institutions of higher learning is regular, and teaching quality must be strictly followed in order to improve teaching quality. Teaching laws have the function of conventions, such as the law of dialectical unity of the interaction between teaching and learning, the law of students development depending on knowledge imparting, and the law of teaching effect depending on the harmonious optimization of teaching system. Only in accordance with these rules can university construction focus on the scientific operation of teaching quality. As shown in Figure 1-1:

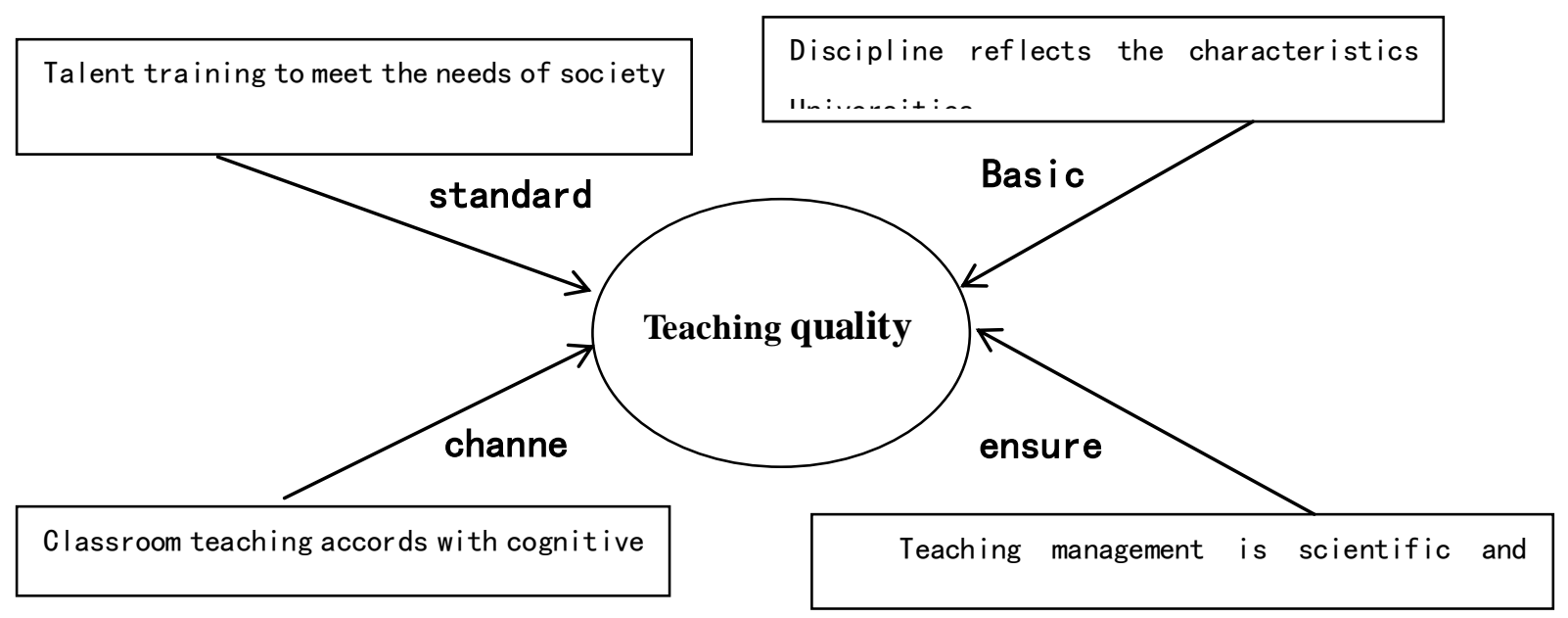

Fig. 1-1 schematic diagram of scientific operation of University Construction

\section{A. Talent Training to Meet the Needs of Society}

The goal of talent training provides a standard for improving teaching quality. Xi Jinping pointed out at the National Education Congress that "efforts should be made to build a comprehensive education system for the cultivation of moral, intellectual, physical and artistic workers, so as to form a higher level of personnel training system." Talent training in universities should focus on this requirement and establish training objectives. First, establish a scientific personnel training mechanism. If universities want to occupy a place in today's fierce market competition environment, they must take the market as the guide, make the trained talents adapt to the national development, meet the social needs, and meet the needs of the rapid development of the information age. The two is to build a reasonable talent training mode. Institutions of higher learning should reconstruct the discipline system, teaching system, textbook system and management system, especially adjust the 
course content and structure in time, and strive to build high-quality teaching team to meet the requirements of personnel training in the new era. Three is to enhance students' social service ability. In 2010, China promulgated the National Outline of Medium and Long-term Educational Reform and Development (2010-2020), which clearly put forward that higher education should "improve the quality of personnel training" and "enhance social service capacity". Therefore, colleges and universities should always adhere to the "root-oriented", promote the "four regressions", take the quality of undergraduate teaching as the lifeline of the school, and construct a "two-class" vision of talent training system, so as to realize the great rejuvenation of the Chinese nation to provide a strong talent, intelligence and scientific and technological support.

\section{B. Discipline Reflects the Characteristics of Colleges and Universities.}

Characteristic disciplines and disciplines lay the foundation for improving teaching quality. In order to improve the teaching quality, universities must take the establishment of characteristic disciplines as a breakthrough point, draw the overall innovation of the discipline system, and form a discipline and professional system with its own characteristics. Firstly, according to the requirements of "optimizing the structure, choosing the right weight to support and forming the characteristics", we should reorganize the professional structure, break the professional boundaries, optimize the allocation of educational resources, and strive to cultivate high-quality talents to meet the needs of the society in the new era. Secondly, in accordance with the requirements of "establishing a scientific, comprehensive and advanced content system to follow the development of science and technology, and to meet the requirements of the times", a teaching system should be constructed that combines compulsory courses, elective courses and self-taught courses, and integrates natural science, humanities, information science and other disciplines. We should carry out heuristic, research and informational teaching, and constantly innovate teaching methods, learning methods and examination methods. Three, we must adhere to the principle of "strict administration of schools" and adhere to the principle of "putting people first, and combining leniency with severity". We should integrate teaching, learning, management, preservation and research into a whole, pay close attention to the construction of teaching style, study style and examination style, and create a good management and education environment.

\section{Classroom Teaching Accords with the Law of Cognition.}

Doing well in classroom teaching is the main channel to improve teaching quality. Classroom teaching is a cognitive activity with a clear purpose. It must conform to the cognitive law. Cognitive law is the law that an individual objectively exists in the cognitive activities of grasping the nature and laws of objective things by means of sensation, perception, representation, memory and thinking. In order to conform to the law of cognition, the teaching contents must be designed rationally, the teaching implementation must be organized scientifically, the effective teaching methods should be used, and a good teaching environment must be created. For example, in accordance with the inherent logic of the curriculum knowledge system to determine the content of teaching, so that step-by-step, interlinked; to adopt teaching methods that meet the needs of the curriculum, conducive to students' acceptance, inspire students to think; to create mutual exchanges, mutual learning, teacher-student interaction classroom atmosphere.

\section{Teaching Management is Scientific and Rigorous.}

Strengthening teaching management is the guarantee of improving teaching quality. Teaching management is a comprehensive management of teaching process, including teaching process management, teaching business management, teaching quality management, etc. First, update management concepts. To truly improve the quality of teaching as a measure of the basic standards of teaching management level, establish all for teaching, all obey teaching, all service teaching management concept. We must not interfere with the management of the teaching center, nor can we influence the management of teaching quality. Two is to strengthen the system construction. Taking the "double first-class" construction as an opportunity, this paper finds out the problems of "unsuitability" and "inconsistency" in the teaching management system and management mechanism. We should do a good job in establishing rules and regulations and establish a scientific, forward-looking and standardized teaching management system. The three is to form an upper and 
lower resultant force. The whole school should actively and actively manage the teaching work. Correctly handle the relationship between teaching management and administration. On the basis of earnestly implementing various teaching management systems, new theories and new methods of teaching management are constantly explored.

\section{Identify the Starting Points, and Strive to Improve Teaching Quality in the Connotation Development of Colleges and Universities.}

Teaching quality is a comprehensive index, and its level depends on many factors. It includes not only the teaching staff, teaching experimental equipment conditions, the application of modern educational means and other hardware factors, but also school-running ideas, teaching management, professional construction, curriculum and teaching materials construction and other software factors. To improve teaching quality, we need to lay stress on the key points and definite goals. As shown in Figure 2-2:

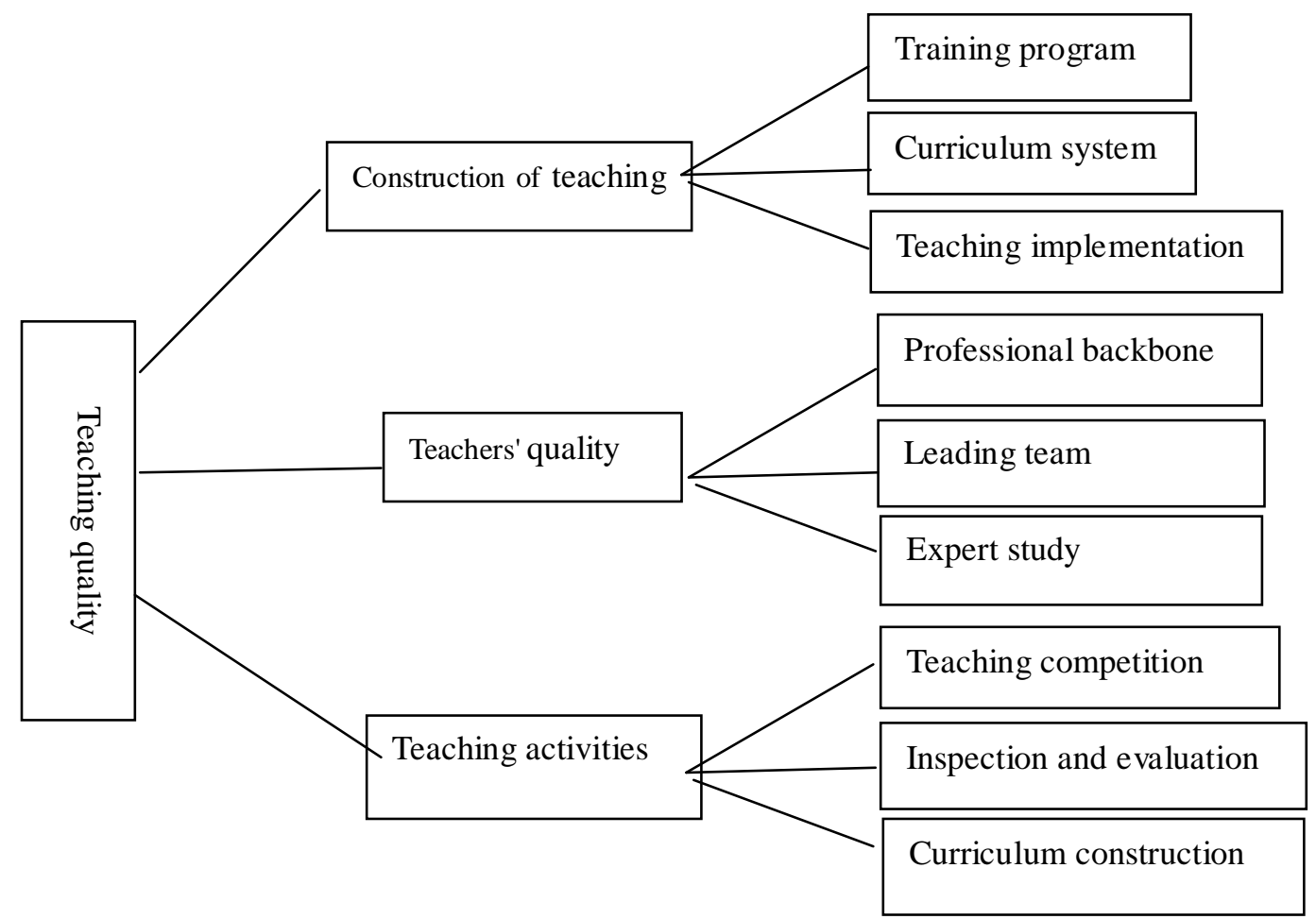

Fig. 2-2 schematic diagram of "three grasping points" in teaching quality

\section{A. Grasping the Construction of Teaching System}

The teaching system is a unified whole composed of the knowledge structure frame, the teaching content design, the teaching method design, the teaching process design and the teaching result evaluation of the teaching process. First, determine the training plan. We should take the quality of talent training as the core, the innovation and practice of talent training mode as the basis, and constantly strengthen the combination of "learning" and "using". We should revise the personnel training program in time to ensure that it can reflect the achievements of specialty construction in Colleges and universities and the changes of social demand for talents in time. The two is the construction of curriculum system. Firmly establish the curriculum concept that reflects the characteristics of the times. Rationally arrange the proportion of each professional course group and subject group. Correctly handle the relationship between theoretical curriculum and practical curriculum, natural science education curriculum and Humanities and social sciences education curriculum, explicit curriculum and hidden curriculum. So that the whole curriculum system can be effectively unified and the quality of applied talents training should be continuously improved. The 
three is teaching preparation. According to the teaching object, teaching content and teaching requirements, teachers should make solid preparations for class preparation, homework correction, extra-curricular guidance, performance evaluation and other links. Teaching management departments should also do a good job in organizing, guiding and checking to ensure the formation of a closed loop of teaching.

\section{B. Grasping the Quality of Teachers}

The quality of teachers directly determines the quality of teaching. Therefore, focusing on the goal of "double first-class" construction, focusing on key areas, key levels, key posts, and constantly improve the overall quality of the teaching staff. First, gather professional backbone according to the requirement of "comprehensive". We should give full play to the role of professional backbone teachers in academic leadership. Adhere to the combination of use and training, in the development and utilization of existing human resources on the basis of strengthening the selection and training of various types of personnel. Adhere to current needs and long-term development. While introducing talents in urgent need, we should aim at saving talents for the long-term development, improving the structure and strengthening the contingent. The two is to forge a leading team according to the requirements of "elite". Elite education requires the first-class teachers to train students into elite talents with solid cultural foundation, comprehensive quality, innovative spirit and practical ability. This requires the implementation of the "famous teacher strategy project". We should intensify the introduction and training of high-level talents and strive to break through the "bottleneck" of the shortage of qualified personnel. The three is to play the role of experts in accordance with the requirements of "first class". In the course of discipline development and scientific research, experts should be given the right to speak, fund and autonomy, so as to fully listen to the opinions of experts and initiate expert research to solve professional problems.

\section{Grasping Important Teaching Activities}

Major activities such as teaching competition, research and communication will be an important means to improve teaching quality. Universities should actively participate in various major teaching activities and strive to achieve excellent results. First, we must treat the quality class competition correctly. By participating in teaching competitions, we can conscientiously sum up experience and find out the existing problems, so as to train the team, form a team and improve the teaching level of the course. The two is to carefully prepare the examination and assessment of teaching quality. We should strictly control the assessment indicators and provide a good teaching environment through improving teaching conditions. Through strengthening the teaching management to carry out effective monitoring and control of teaching, the important links that directly affect the teaching quality in teaching activities should be taken as control points, and the inspection and examination should be strengthened to realize the overall improvement of teaching quality. Three, we should strengthen the construction of quality courses and quality courses. Through scientific demonstration, careful selection, careful planning and increasing investment, universities should strive to build more courses into high-quality courses and quality courses, so as to promote the quality of teaching by curriculum construction.

\section{Reference}

[1] Xi Jinping. Decided to build a well-off society in an all-round way and win the great victory of socialism with Chinese characteristics in the new era [M]. Beijing: People's Publishing House, 2017.

[2] Xi Jinping. Speech at the National Education Conference [N]. people's daily, 2018-09-11 (1).

[3] Xinhua news agency. The CPC Central Committee and the State Council issued 《Outline of the national medium and long term educational reform and development plan $(2010-2020)\rangle$. [N]. Guangming Daily, 2010-07-30 (1).

[4] Hong Chengwen. What are the international experiences in the development of world class disciplines [J]. Chinese higher education, 2018, (5). 